\title{
A Research Agenda for International Business and Management: the promises and prospects of thinking outside the box
}

\author{
Mike Geppert and Ödül Bozkurt
}

\subsection{Introduction}

Over the past two decades there has been no shortage of reflective commentary on the state of research in International Business and Management (IB/M ${ }^{1}$ or of efforts to identify what needs to be studied next and which avenues of research are most promising. Meta-analyses of popular themes in extant academic literature and suggestions for future IB/M research agendas are not new or uncommon (see e.g. Buckley, 1996). However, especially in the last ten years articles taking stock of the preoccupations and output of the field have become more overtly critical. From fundamentally descriptive and lightly speculative discussions about what lies ahead for IB/M in terms of focal topics and themes, reflections have moved on to pointing at a state of "crisis" in the discipline; a dead end for research and thinking. Increasingly serious, indeed disconcerted appraisals even from mainstream scholars have taken on a tone of "wake-up" calls, like that by Delios (2017), advocating not just reform but a far more comprehensive "rebirth" of the field. Leading scholars have conjoined their demands to "revitalise" the whole discipline by demanding a rethink of core theories, topics and methods, and in particular a redefinition of IB/M's remit to include the "big questions" (Buckley et al., 2017). IB/M scholars are increasingly implored to think out of the box in their future research and collectively invigorate their shared intellectual domain. These deliberations have been taking place against a backdrop of both persistence on established ways of thinking and rising concerns about disciplinary distinctiveness. On the one 
hand, an institutional infrastructure of IB/M comprising disciplinary associations, conferences and journals of prestige remains formative of the scholarly community and indeed its internal power dynamics and hierarchies. On the other hand, it is argued that "IB scholars' disciplinary identity is on the block" (Michailova and Tienari, 2014: 52). Old friends of the field in economics and strategy have for some time been seen as "major competitors" (Shenkar, 2004) increasingly encroaching or even usurping the disciplinary domain.

Here our volume comes into play. We are interested in what such out of the box type of research could be, what it might look like and what it will involve doing. When starting the journey of our book project, we asked all contributors and our commentator to draw on their specific expertise and recent research to reflect more broadly on which directions they felt future IB/M research needs to move in. We invited authors from among the most established names in $\mathrm{IB} / \mathrm{M}$, and also scholars who probe a range of issues directly linked to international business and management activity in related disciplines including strategy, sociology and political science. By bringing together scholars of varying levels of embeddedness in the academic field of IB/M in this small sandpit, we responded to the repeated calls for bringing diverse voices into the discussion and avoiding identikit thinking. The book shares our authors' thoughts on how they see IB/M as a discipline moving in the future and their suggestions for how that path may best be charted.

In this introductory chapter we provide an overview of the context for the ensuing discussion. First, we summarise what mainstream IB/M scholars have identified as the key problems of the field, why some of them have seen it to be in crisis and the kind of research agendas they have proposed for future studies. Next, we consider the overtures for closer engagement with research from the growing sphere of "critical perspectives on IB" and the suggestions generated from this perspective towards making the whole field more critically reflective and relevant (again). Having set the background scene, we turn to the ten substantive contributions and the subsequent commentary chapter of this volume. We introduce each chapter by briefly characterising the contents and drawing out the recommendations they put forth for a future research agenda in $\mathrm{IB} / \mathrm{M}$. 


\subsection{The perpetual crisis of IB/M and proposals from the mainstream}

International Business (IB) emerged as a distinct academic field in the post-war era, particularly coming into its own amidst the boom of advanced Western economies and the international business activity linked with that context, in the mid-1950s (Engwall et al., 2018: 1080). Research from this initial self-consolidation period has focused on and still largely concentrates on economics-based accounts aiming to explain a rather limited number of key issues and foremost international trade, foreign direct investment (FDI) and, with the most emphasis, the emergence, role and function of the multinational enterprise (MNE) as a tool for internationalisation. Later on a big " $M$ " for "Management" has been added to studies in IB after the field started to open up to research from management and organisation studies. This stream of research developed largely parallel to mainstream IB, with a strong functionalist bias in the study of the MNE (Ghoshal and Westney, 1993). The field also began to engage in the study and comparison of small and medium-sized international businesses, in addition to the large MNEs that had in earlier years been the rather exclusive organisational form in focus. More recently IB/M scholars have discovered the usefulness of mainstream sociological theories, and in particular comparative and neo-institutionalism as conceptual lenses for making new sense of old problems, such as home and host country-specific influences on MNEs (see e.g. Buckley, 2002; Engwall et al., 2018; Meyer and Peng, 2016).

Notwithstanding the changing contours and scope of $\mathrm{IB} / \mathrm{M}$, however, the opening up to neighbouring disciplines did not quite trigger the kind of revitalisation and engagement with new and critical conceptual ideas that figurehead scholars called and hoped for (Dörrenbächer and Geppert, 2017). Wider societal and ecological issues have hardly been considered and if so, rather reluctantly and peripherally, and just in the last decade. Whether this was due to a general disregard for the call and (international) "business as usual" being the path of least resistance for most scholars, or if there were shortcomings in the execution of attempts to truly engage with interdisciplinary insights can be debated. Regardless, from the 1990s onwards there has been a rise of depictions of the discipline in crisis. The most important problem raised has been the almost indignant persistence of the narrow focus of most IB/M studies on a limited number of issues and especially the internationalisation processes of MNEs, i.e. their strategies and structures, often through increasingly complex measures of performance based on quantitative research methods and data, the latter increasingly from third-party databases. Arguably the buckling down 
on the MNE may also have been aggravated by IB/M's simultaneous efforts to retain and highlight its distinctiveness as a discipline - some influential scholars explicitly making the case that sticking to what it does best constitutes the field's "comparative advantage" and that IB/M's best path forward would be to home in on its primordial question, "What determines the international success and failure of firms?” (Peng, 2004: 105).

Another - and in the field highly recognised - call by Buckley (2002) sought to strike both a self-appreciative tone by asking to reflect on the field's past achievements and a self-transformative tone by noting it was "running out of steam" and proposing major reforms. The crisis discourse in IB/M has not abated since, with many arguing that what academics are producing has increasingly become irrelevant for the real-life problems of policymakers, practitioners and citizens (see e.g. Cheng et al., 2009). Warnings follow from these observations that the outcome of the crisis may well see IB/M "decline further in impact, insight and status" (Cheng et al., 2009: 1073). In this sense, the aforementioned claim by Delios (2017) that IB/M requires nothing less than a "rebirth" is more an emphatic re-statement of long-standing views rather than an idiosyncratic intervention. He delivers the message with dramatic flair, but the concern that the field has become detached from new phenomena in the globalising world and fails to explain anything new is shared by many. The position taken here, that radical change instead of incremental reforms is needed to revitalise the field, may not be as widely shared, however. Most mainstream debates on the crisis, if they agree with the term, focus on decidedly more incremental reforms. Let's concentrate therefore on the reformist views and have a closer look at what leading scholars suggest.

First, there is an ongoing demand that $\mathrm{IB} / \mathrm{M}$ studies need to go beyond the classical topics like FDI or the MNE. Accordingly, review articles in core $\mathrm{IB} / \mathrm{M}$ journals propose that the work within the field needs to open up and propose a series of novel topics that a future research agenda should include. These recommendations range from focusing on security issues and risks of terrorism (see e.g. Griffith et al., 2008; Henisz et al., 2010) to the study of the impact of new technological developments and the role of Information and Communication Technologies (ICT) on internationalisation processes (see e.g. Aharoni and Brock, 2010; Engwall et al., 2018). However, the suggested novel topics for the IB/M research agenda often look random, mostly presenting the research interests of the authors of the review articles and an expression of the zeitgeist of popular themes, with little coherent justification establishing links to the discipline. They often seem like lists of topics seen as pressing, even "hot" at a certain moment in time, and consequently often end up without lasting effects on the research agenda. 
Second, there is an ongoing call for interdisciplinarity. Classical IB/M theories and conceptual constructs are depicted as having made important contributions, but also as being too narrow for expanding the research agenda and insufficient for opening up conceptually to address "topics that matter", i.e. for contributing to an understanding of issues of immediate relevance for the world of practice. IB/M scholars are repeatedly implored to engage with research and researchers in neighbouring fields of the social sciences. Accordingly, to make sense of a complex world research has to be multidisciplinary so that multiple phenomena like cultural factors, technological advances, political, economic, organisational and managerial issues can be taken into account simultaneously (Aharoni and Brock, 2010). Interdisciplinarity is demanded not just for new theory-building and discovering new methodological approaches but also for leveraging greater research impact in the wider academic community (Buckley et al., 2017; Seno-Alday, 2010). There seems to be no shortage of ideas as to why interdisciplinarity might help revitalise theorising, research philosophy and methods. In practice, though, multidisciplinary research is rather rare in $\mathrm{IB} / \mathrm{M}$ and if it takes place at all it does not necessarily lead to the outcomes that the authors advocating them may have wished for.

Third, it has also been suggested that IB/M scholars should leave their comfort zones and ask "big questions" and engage with "grand challenges" (Buckley et al., 2017) in a world becoming ever-more globalised and nationally contextualised at the same time (Witt, 2019). These demands go beyond the call for incorporating novel topics into the research agenda and for more interdisciplinarity. Rather, these other acts of reform are to follow from the recalibration of the overall ambition of the discipline and up the ante. Buckley, for so many the bellwether of the field, together with Doh and Benischke, sees the resetting of the field's horizons as a key condition for its future:

Only if IB scholars take grand challenges seriously, accept that these phenomena are distinct, develop innovative research designs, and concede to the sometimes-equivocal nature of their findings, will they develop novel and interesting theoretical insights that are also relevant to society at large. (Buckley et al., 2017: 1061)

The "grand challenges" in question are wide and varied, aligned with urgent societal concerns, including with the gamut of "broader issues such as climate change, poverty, migration, terrorism, and infectious disease" (Buckley et al., 2017: 1046). These are far reaching aims for reforming the classical IB/M research agenda, and certainly highly ambitious. Notably, these calls for such major reforms and change have been made mainly by some of the field's most prominent figures. Many of these influential voices have been prolific 
contributors to the consolidation and continuity of the classical IB/M research agenda, which they now see in desperate need of reform. Leaving aside the question as to whether their omnipresence on both sides of the self-satisfaction vs. desperately-requiring-reform fence may blur the message, it remains to be seen if and how the so-far still rather structural-conservative IB/M academic community will - or can - take the advice on board and fill it with life. In our view most mainstream IB/M studies remain as they were, anchored in the economics tradition and, if going beyond, hardly questioning the rationalistic bias of core theoretical constructs and established methodological techniques. Scholars who are truly interested in reforming, revitalising and thus making their discipline more relevant again may need to think about why this does not happen despite the many highly concerned calls plus the suggestions for ways forward. There are other voices in this conversation, too, and we note some of those next.

\subsection{Critical perspectives in IB/M}

The rise over the past twenty years of the broader body of scholarship under the banner of "Critical Management Studies" (CMS) (Alvesson et al., 2009), characterised by an attempt to offer "a range of alternatives to mainstream management theory with a view to radically transforming management practice" (Adler et al., 2007: 1), has had little intersection with and impact on IB/M on the whole. Nonetheless, along with the calls for a revitalisation and recalibration of focus for the field by mainstream scholars, there has been a slow but clear growth of thinking, theorising and research that has come to be consolidated as "critical perspectives" in IB/M. Like all such challenger perspectives that seek to redefine a domain, this body of work includes offshoots in terms of topics and themes, as well as direct critiques of the mainstream. The matter for critical scholars seems not so much the often tiring academic debates of whether modest reforms versus radical changes in the research agenda are needed. The discontent is much more foundational and the demand for change is more central in the critical perspective. For some, critical IB/M research is in fact an overt "political project" that aims to study and, in the tradition of action research, actively address and deal with the problematic socio-economic and environmental consequences of contemporary international business activities (see e.g. Cairns, 2019).

Specific platforms, fora and outlets matter for anchoring, supporting, and legitimising bodies of research that embody certain perspectives, especially if these are shifting the disciplinary ground, and in this effort the launch of the 
journal critical perspectives on international business (cpoib) in 2005 merits attention. This is not to say that cpoib is the exhaustive manifestation of a critical approach in IB, as many critical studies on classical IB/M themes appear in high impact publications in general management or neighbouring subfields, such as Human Relations, Journal of Management Studies and Organization Studies. ${ }^{2}$ The journal's existence, endurance, and recognition, however, clearly marks the vitality of a "critical" lens in IB/M, as it continues to evolve as new contributors come in, helping to shape the outlet's collective voice. Reflective of its position and mission, cpoib has repeatedly dedicated time to debates on what that might mean, from initial ambitions to offer a "new paradigm" (Cairns and Roberts, 2011: 289) on the heels of the decades that saw globalisation as ever-ascendant to directly targeting discussions in the mainstream about the shortcomings of the discipline (Roberts and Dörrenbächer, 2012: 4). Most recently the editors depict "critical IB studies" as being "concerned with the discussion of the nature and impact of international business activities" (Dörrenbächer and Gammelgaard, 2019: 239), and "objecting to the one-sidedness of managerialist research", situating the field firmly within the CMS mission and agenda. The "critical" is not conceived as an add-on or a complementary sideshow to the mainstream in this vision, cpoib having been developed as a direct "counter-reaction to mainstream IB" by addressing omitted themes and missing theoretical perspectives (Dörrenbächer and Gammelgaard, 2019: 241).

A systematic review of the body of research that has been consolidated in critical IB/M around the specific platform of the cpoib has revealed five salient thematic areas: positioning critical international business research, postcolonial international business studies, effects of international business activities, financialisation and the global financial crisis, and "black international business" and corporate social responsibility (Dörrenbächer and Gammelgaard, 2019: 243). Both in terms of authorship and thematic foci, the journal's endeavour of "challenging the orthodox" (Roberts and Dörrenbächer, 2014, 2016) has yielded a body of research that spends a fair amount of effort on self-reflection, but also one which offers both studies of topics neglected by the mainstream and framing widely studied topics in new, different ways.

Beyond the reshuffling of research topics and themes and the reframing of questions and priorities, the critical perspective offers a fundamental sensibility that diverges from the recent reincarnations of the mainstream in the field. In Cairns' words, this pertains to a foundational recognition that "international business is a political project, with important social and economic implications" (Cairns, 2019: 269) and an aspiration for the field to be "a political and social project for change to what can be, not an academic exercise in observing, 
measuring and reporting what is" (Cairns, 2019: 269). Such an orientation had indeed been integral to some of the earliest examples of the IB/M canon. Most notably Hymer (1979) applied Marxist theory to his depiction of the MNE, which mainstream IB/M drew on extensively. The gap between the approaches appears to have become harder to bridge, with most efforts from the mainstream remaining largely reformist and incremental whilst the critical IB/M perspective demands a radical, systematic overhaul of the research agenda of the field. In our view the latter does not involve a wholescale abandonment of established mainstream IB research themes, but rather more openness for critical approaches and reflective forms of theorising in the tradition of critical thinking. Indeed, one wonders why critical perspectives have so far had only limited impact on IB/M generally, since many of the disciplinary reorientation prompts offered up by the critical agenda in fact align closely with the more intramural misgivings of the mainstream. We next look at several obstacles that stymie the fruitful and, as agreed by all sides, needed, transformation of the field and the opening up of an invigorated future research agenda.

\subsection{Obstacles to overcome and thinking outside the box}

As academics whose research in the IB/M domain draws on organisation studies, economic sociology, and the sociology of work, the merits of cross-disciplinary curiosity are obvious to us and the failure of mainstream and critical IB/M communities to speak to each other striking. This is especially so given the extent of overlap in the calls for attention to themes by scholars from both orientations (Dörrenbächer and Gammelgaard, 2019: 253). Indeed, a small number of scholars have been able to claim space and voice their views in journals and platforms visible and attended by others from both critical and mainstream approaches, but by all measures cross-fertilisation remains difficult and extremely limited. Cairns (2019: 264) even ponders whether IB/M "deserves" the dismissal by critical management studies scholars who see more potential for transforming the core debates in other subfields such as organisation studies, human resource management, or even strategy, but think the critical project in IB/M is hopeless in terms of having a real impact.

The mainstream does not bear the title without a reason: it is the dominant, indeed often the hegemonic framing of IB/M and it has institutional, social and intellectual consolidation, legitimacy and momentum. It also claims a far greater segment of the "workforce" that produces the IB/M scholarship, working according to its principles and rules. With these inevitably come 
entrenched hierarchies of knowledge and methodologies, reflected in the unease with which even IB and IM relate to one another as disciplinary fields and groups of scholars, with the former typically claiming more weight and status even if implicitly. A degree of alignment in any disciplinary community propels collective knowledge generation by providing a critical mass of curiosity and scholarship around certain key themes and research agendas, but too much closure renders the collective unable to renew itself. In particular, we find that three key obstacles limit the promise of most of the reformist, mainstream calls for dealing with the crisis in the field.

Firstly, we observe that the specific treatment of proposals for "theory development" take a certain approach to what is meant by "theory", one which continues to take as the main referent the delimited version of IB/M predicated on the centrality of the MNE, its internationalisation and an economistic explanation of everything entailed therein. While this theory may offer avenues of exploration yielding novel insights, we would argue that any significant theoretical reinvigoration of the field will need to think of Theory with a capital T, and dare to seek more substantial breaks from "establishment IB/M". ${ }^{3}$

Secondly, theoretical calcification is closely intertwined with epistemological and hence also methodological single-mindedness, all the way to the tipping point into solipsism. A brief glance over key conferences and journals in the field will confirm that there is more than a faint suggestion that IB/M may be encroaching on such intellectual territory. It is widely known and curiously just as widely accepted that methodologically the field has become increasingly more quantitative, at the expense especially of in-depth qualitative research which, even though it has produced some of the most significant milestones of the discipline, remains at the periphery. The quantitative techniques applied in the field have become more sophisticated than ever before, fed and fuelled as they are by the availability and promises of large data sets, almost exclusively compiled and offered for purchase through software packages and subscriptions by third parties. Anecdotally, it is increasingly less common to find the IB/M scholar who collects their own primary, customised data. Methodologies help us generate insights not in terms of their pure qualities but by how appropriately they are used and applied to the relevant research questions. We take the risk of research becoming data-driven, as opposed to generating the data its questions demand. The latter has become a particularly important problem in the field.

Thirdly, we note the implications of the calls for reform or for revolution for expectations that scholars will rise to the challenge of being reformers and revolutionaries. Who, specifically, are we counting on to overhaul, reimagine and 
revamp the $\mathrm{IB} / \mathrm{M}$ agenda, rendering it exciting, insightful and perhaps most importantly, relevant beyond the confines of academia and to a wide range of external stakeholders? Where will they come from? Why will they have chosen IB/M as the home for their intellectual efforts? Most calls for change currently come from established scholars, especially senior professors. They are, at least in the case of the UK, just as likely to have had their undergraduate and postgraduate training in a range of disciplines other than IB/M, including economics, sociology and other social sciences. This has presumably equipped them with broader awareness of disciplinary strengths (and limitations) on the whole. For the younger generations of scholars that have come of age in the era of the ever-ascendant Business School, it is much harder to imagine where the exposure to, let alone engagement with, some of the core paradigms, debates and theoretical frameworks of relevant related disciplines would have been possible. As the calls for multidisciplinarity, methodological pluralism and theoretical agility mount, it may ironically, if not sadly, be the case that the community of scholars expected to deliver on these are rather ill-equipped and poorly socialised to do so. Many young IB/M scholars' careers are further streamlined by the strict and increasingly standardised reward systems of Business Schools and departments, pressuring them to publish in the "top ranked" IB/M journals, which remain largely conservative in their openness for novel critical themes and methods, especially if these are not delivered with the mastery of highly experienced academics. Only this approach enables junior scholars to move up in the hierarchy of the field. The institutionalised occupational sanctions of the field go a long way in explaining why even modest calls for reforms in the field's research agenda, which largely come from senior scholars, might fall on deaf ears in the less established cohorts.

We make no mistake and note that current $\mathrm{IB} / \mathrm{M}$ research is exceedingly "rigorous", but would further add that it is mainly so in its own terms. Such "rigour" is often invoked in the dismissal of the critical agenda as digressive, imprecise, even irrelevant; i.e. outside the scope of IB/M. On the other hand, some of the empirical ambition, conceptual precision and analytical leverage offered by best examples of mainstream IB/M remain underappreciated and underutilised by those adopting a critical approach. The wealth of insights the field has produced on the organisational form of the MNE and its internal workings, both theoretically and empirically, open up rather than block some of the lines of inquiry espoused by the critical perspective. Many insights generated by mainstream IB/M can be effectively utilised to tackle new questions from outside the proverbial canonical box, helping a critical understanding of a broad range of issues such as green washing, slave work in global value chains, international crime (Enderwick, 2019) and others. Whilst we cherish the value of divergent perspectives for intellectual growth, and are not propo- 
nents of the "why can't we all get along" school of anodyne, non-committal commentary, we do think there is extremely fruitful terrain to cover in IB/M by those who share the will and ability to "think outside the box" and who can remain open-minded about at least some of their theoretical convictions.

\subsection{This book: looking ahead and thinking outside the box}

This book aims to engage with calls from both mainstream and critical voices for a renewal and revitalisation of IB/M research by offering the space to contemplate to a diverse group of scholars. Our contributors come from various walks of IB/M life, from different persuasions, subfields of interest, disciplinary backgrounds and geographical locations - the diversity was very much intentional, though of course as always, still partial. We invited them to reflect on the state of the field and its future in an open-ended way, but did encourage them to be at their imaginative, even provocative best. After several months of gestation of initial ideas and the development of full contributions, the group had the bitter-sweet fortune of holding one of the last face-to-face meetings in March 2020 in Jena before COVID-19 stopped such academic forums. Debate was multi-directional with contributors having envisioned the research agenda for IB/M in different ways, but what they all had in common was an effort to draw on their various expertise to "think out of the box".

The eleven chapters that follow provide a range of new directions, correctives, suggestions, nudges, invitations and road maps for the future of IB/M. They have many points of intersection and could have been interwoven in myriad ways, but taken together we found them chiselling the research agenda for the field in four broad ways: revisiting core IB/M theories; contemplating the changing relationship between nation-states and MNEs; drawing attention to power and ideology in international management; and studying and theorising new phenomena. The volume is not an exhaustive grand statement prescribing a particular research agenda, but rather through these chapters we highlight and offer some of the most promising openings and opportunities for the re-energising of the field urged by all.

The three chapters of Part I revisit classical concepts of mainstream IB/M and suggest novel ways of looking at and dealing with them. The authors offer new ways of thinking out of the classical IB "toolbox" when looking at "factoryless good producers" (FGPs), which resist accurate capture within the common conceptual model of internalisation theory (Chapter 2). They also question 
whether core rationalistic ideas about objectivity and rationality of managerial decisions in regard of international expansions can capture the heterogeneity of observed managerial and firm behaviour (Chapter 3). Additionally, mainstream "canonical" models of internationalisation and outward FDI of emerging market MNEs are revisited and criticised for overlooking and failing to explain novel developments (Chapter 4).

Roger Strange's chapter raises the question as to whether "we need a theory of externalisation" in future studies on MNEs, and argues that this is needed because novel forms of coordination in lately evolving forms of contemporary MNEs can hardly be understood when applying some core concepts out of the IB/M toolbox. Classic IB/M theories are presented as being historically-bound. The internalisation approach is seen as having been suitable for the study of direct ownership and hierarchical MNEs in the post-war era but not when it comes to the study of evolving FGPs. FGPs are portrayed as an empirical puzzle, managing and controlling their business activities in different ways than the classic transaction-cost efficient MNE, in ways that can hardly be captured in internalisation theory-based models. In FGPs we are confronted with the ineffectiveness both of direct ownership and strict forms of hierarchical integration and this, it is argued, requires alternative ways of theorising. Accordingly, a theory of externalisation is outlined in order to shed light on newly emerging asymmetric power relations, which play an even more crucial role when it comes to the control of contract manufacturers and external suppliers. Future studies, it is concluded, need to go beyond the current focus on FGPs which originate from advanced economies though and study novel FGPs that pop up in emerging economies. In such home country contexts scholars need to be especially aware, it is further argued, of the distinct "institutional, economic and/or other characteristics of their home countries".

The next chapter by Giulio Nardella, Rajneesh Narula and Irina Surdu starts with a critique of the rationalistic bias in mainstream IB/M theorising. The authors point to the limits of the micro-foundations in the field which often presents the strategic choices of international managers as being objective and unilateral, without paying adequate attention to context-specific and multi-faceted aspects of real-life decision-making processes. The contributors suggest looking into the potential of behavioural concepts, such as cognitive biases, heuristics and reference points and how applying these ideas might be fruitful to enrich and complement future IB/M theorising. These critical reflections on non-rational and ex-post rationalisation of internalisation decisions lead to the authors' proposing various routes for future studies that would pursue the outlined behavioural perspective of international management. The suggested research questions focus consequently on behavioural aspects 
of MNE strategic choices, managerial biases and organisational behaviour, behavioural aspects of firm governance, and new methodologies. Especially the latter issue is seen as essential for "making these micro-foundational concepts actionable in international business management research". This is a focal quest which has been brought up in many chapters of our volume, and most pronounced in Chapter 11.

The final chapter in this section by Suma Athreye revisits established theories on internationalisation in the field and focuses especially on the conceptual limitations of the FSA/CSA (firm specific advances/country specific advances) framework. The model has been developed and tested for the study of internationalisation activities of Western MNEs. The author first shows how and why the FSA/CAS framework is ill-equipped to conceptually capture and properly explain internationalisation processes of emerging multinational enterprises (EMNEs). Based on her own and other empirical studies the author shows that EMNEs' outward investment strategies differ significantly from what established internationalisation theories would predict. Three important observations are highlighted: (a) that EMNEs were able to raise money for overseas foreign investment when it was not available in the home country, (b) that EMNEs' high growth in export volumes is closely linked with major advances in terms of trade, as illustrated by the way four BRIC country governments became major net foreign (currency) creditors, and (c) that data on millionaire migration can be linked with the role of corruption legacies in home countries, which has significantly determined the direction of outward FDI flows. Given the problems with established models the author proposes a "real option framework" which is understood as being "capable of incorporating the realities of EMNE expansion far better than the FSA/CSA framework". Finally, the crucial role of interdisciplinarity is highlighted which in the author's view needs to be on top of a future research agenda.

Chapters 5 and 6 in Part II focus on the central object of many studies in IB/M and indeed the field itself: the MNE. Both reflect on the changing relationship between the MNE and the nation-state. In the centre of interest is the question of how MNEs are linked with nation-states and other internationally operating key actors when dealing with national and transnational institutional constraints in order to enable and support thriving internationalisation activities. Chapter 5 revisits established IB/M research on the role of home country institutions and points to an important research gap when it comes to the role of specific home country measures (HCMs) provided by governments and associated actors in order to support firm internationalisation. Chapter 6 looks into the increased importance of close interactions between states and MNEs 
with a special interest in the role of MNE diplomacy, which has hardly been acknowledged and studied in contemporary IB/M research.

Florian Becker-Ritterspach and Khaled Fourati look anew at home country influences on internationalisation of MNEs. First, they review four established mainstream IB/M frameworks and how these have dealt with the role of the home country in firm internationalisation. Additionally, they review insights from culturalist and institutionalist, so-called country-of-origin effects studies and conclude that most of the former research has hardly paid attention to how national governments support internationalisation with concrete HCMs. For the latter, however, they especially find the growing body of studies on EMNEs relevant because this stream of research pays not just more but also more detailed attention to how home country institutions prove both enabling and constraining for the "capacity of the MNEs to access needed resources externally". They then look closer into an emerging field of study, focusing on HCMs that national governments employ to promote and support their MNEs. Accordingly, a key point of reference in the outlined research agenda is the quest for shedding more light on the antecedents, patterns and consequences of HCMs. Becker-Ritterspach and Fourati further want future researchers on HCMs to concentrate their research efforts on crucial questions like (a) how countries differ in their firm internationalisation measures, (b) how imprinting of home country institutions influences the success and failure in certain host country contexts, and (c) how the extent and willingness of home countries to provide distinct support measures abroad matter when it comes to developing the lasting competitive advantages of the MNE.

In his chapter Brent Burmester argues that MNEs need to continuously mediate all kinds of divides, be it social, cultural, institutional and geopolitical, which emerge between the MNE itself and other key international actors. The role of MNEs in the newly emerging international arena is seen as diplomatic because they are political actors that need to interact with other powerful international players when dealing with those increasingly complex divides, here described as "estrangements", in order to produce and reproduce a thriving "international society". The author criticises IB/M for not paying sufficient attention to these socio-political developments, despite having the MNE in the centre of interest of research since the field was established. The main reason for this neglect is seen in the narrowing of theoretical and empirical research on the economic functioning of the MNE, which has downplayed its important diplomatic role in the economy and society. The diplomatic role of MNEs is described as essential because "they, more than any other international actor, enact the totality of practices that characterise the contemporary global political economy". It is emphasised that early IB research, before the economistic 
turn, actually dealt with the many non-economic roles of international firms but then abandoned these interests, and thus never developed an agenda for the study of the diplomatic role of MNEs. Accordingly, the development of a research agenda for the study of MNE diplomacy is seen as overdue in IB/M, as Burmester stresses that such an endeavour would provide the opportunity to revisit insights from earlier work and combine these ideas with deep insights, developed in neighbouring subfields in the wider social sciences which have never neglected the important non-economic roles that MNEs play as international actors.

While the first two sections thereby prompt rethinking some of the best trodden ground of IB/M, the contributions in Part III are joined in calling attention to themes that the field has only sporadically engaged with, and almost always at the margins: the role and importance of power relations and ideology in international management.

In Chapter 7, Leo McCann, Brian Wierman and Edward Granter invite the field to "treat ideology seriously". Through a discussion of the empirical cases of two management fads, "Holacracy" and "Evolutionary Teal Organizations", they highlight how "hypermediated, 'faddish' products" like these constitute a part of international management knowledge that has so far gone under-recognised and under-researched. Their empirical examples would appear "not like IB/M" to mainstream researchers but provide astute and highly recognisable examples of management principles and aspirations that are disseminated internationally, beyond the boundaries of individual MNEs. This probe into the global circulation of business ideologies leads the team to a number of proposals for a future research agenda: a linking of IB/M with the rich knowledge on the "promotion, circulation and translation of management knowledge", the exploration of the "nature of discourses that constitute business ideology" (including in comparative perspective), the study of such ideology and knowledge production as big and growing global business itself, and attending to the "need to better understand the real-world impacts of business ideology". This is a contribution that not only challenges the hardened disciplinary boundaries of IB/M as embodied in the field's key outlets, curriculum and institutions, but which also directly confronts the national-culturalist paradigm that, in its many revised guises, still dominates international management (and especially international human resource management).

Ursula Mense-Petermann also sees power relations and the importance of conceptual repertoires in which actors understand business and management as necessary and important main arteries in the future IB/M research agenda, but draws us back into the MNE to discuss how these matter to the central 
institution of the field. In particular, she notes that despite the growing literature on emerging economy multinationals (EMNEs), we still understand too little about their internal workings, their geopolitical embeddedness, and how these are tightly intertwined. For Mense-Petermann, research on these themes should sidestep the mere replication of the hitherto dominant modes of inquiry and needs to focus on the real-life practices over abstract strategy by firms, and on the micro-political negotiations around these by actors. Specifically, she advocates the adoption of a sensemaking approach for the recommended integration of an understanding of actors' agency and the organisational context. Incorporating insights from post-colonial scholarship on domination effects, this lens could prove highly revelatory in understanding how socially constructed hierarchical orders between cultures' identities are negotiated and enacted inside the EMNE. Without contending with such power relations and sensemaking, IB/M's treatment of EMNE internationalisation will remain seriously compromised. Ethnographic research in particular promises to be the best suited methodological tool for the task at hand. Chapter 8 concludes with confidence that despite challenges, the scholarly community will find ways to carry out in-depth qualitative fieldwork, as efforts will be well worth the empirical rewards.

Finally, in Part IV our volume has three chapters that honour the calls for revision and relevance in $\mathrm{IB} / \mathrm{M}$ by engaging in the study of novel phenomena and developing new theory to enable us to do so. Chapters 9, 10 and 11 all contribute to the revision effort by highlighting topics that are increasingly more salient in the empirical world of IB/M, as well as offering concrete theoretical and methodological proposals for how we can go about engaging with them.

Verena Girschik and Jasper Hotho's contribution, Chapter 9, is on the progressively more prominent roles MNEs play in societal crises today, across a wide spectrum of situations ranging from armed conflict to humanitarian emergencies. As we were starkly reminded in the days of the COVID-19 pandemic during which we have put this volume together, societal crises and the need for humanitarian action they create involve not only public and third sector organisations but also businesses, including multinationals. Girschik and Hotho's review of extant IB/M scholarship on MNE activity in relation to / at times of crises highlights the complexity of this relationship and the need to approach it with great contextual sensitivity. Drawing particularly on the case of the shipping industry and the migration crisis in the Mediterranean over recent years, they highlight three observations about MNE involvement in societal crises. Taken together these observations challenge the dominant approach in extant scholarship which reduces the explanation of MNE behaviour in face of crises to cost minimisation and/or risk avoidance, following 
economistic theories of the firm. According to the authors, MNEs have other motivations in engaging or disengaging with crises beyond risk minimisation; the "conventional dependent variables" of IB research - location, investment and exit - cannot capture the highly variable ways in which MNEs (have to) respond to crises in their daily operations. Furthermore, rather than being generated solely by the external environment, societal crises are influenced and shaped by MNE activity. These are important, immediate phenomena that rightfully deserve attention in the research agenda for the field.

In Chapter 10, Christoph Dörrenbächer and Lukas Ellermann turn to one of "the most evil phenomena in International Business", modern slavery. Besides being an excellent example of how IB/M scholars can incorporate new empirical developments into the disciplinary domain, this contribution also demonstrates how they can do this by engaging with, rather than dismissing, previous treatments of the subject matter. Dörrenbächer and Ellermann explore the conditions that enable modern slavery first through a multidisciplinary literature review, then engaging closely with the most influential work on the topic from within business and management studies, that of Crane. Taking up the five macro-institutional contextual variables that this theory posits define the incidence of modern slavery across different economies, the authors discuss how these can be operationalised for empirical analysis that would allow comparisons. Walking us through this effort for the variables of regulatory, socio-economic, industry and geographic contexts, the chapter elaborates further on the fifth variable in Crane's theory of modern slavery cultural context. The authors draw on the extensive, if potentially contentious, data accumulated in IB/M scholarship on the cultural context using Hofstede's theory of the six dimensions to probe cross-correlations with data on modern slavery. The conclusions are not definitive, but the chapter illustrates how the reiterative inquiry into new topics would draw on and develop data and theory from established debates in the field, and how the research agenda of the field can involve empirical studies utilising the accumulated insights of the discipline.

Novel phenomena by definition are constantly changing and the final substantive contribution in the volume, Chapter 11, offers a proposition for how IB/M can theorise unfolding empirical realities in a complex, dynamic world. Peter Zettinig and Niina Nummela begin by celebrating the heritage of the discipline of finding inspiration and theoretical puzzles in empirical observations, and go on to advocate a futures-oriented perspective for IB/M research to enhance its relevance and practical utility. The emphasis on the plural is intentional, indeed critical, since the authors see an alertness to emerging phenomena and to the multiple possible trajectories and outcomes in time as the lynchpin 
of an approach to $\mathrm{IB} / \mathrm{M}$ research that will render it relevant to a variety of audiences. Recognising that "relevance" is contingent rather than fixed and self-evident, they propose theorising through "envelope" frameworks, as these can be utilised to address the issues different stakeholder groups prioritise and care about in an agile, dynamic way. For IB/M scholarship of the future, such theorising, coupled with a critical realist approach to empirical research, can afford a proactive role and legitimacy beyond the academic community, letting the field regain influence on important stakeholders. Zettinig and Nummela contend we must accept that "there is no theory of everything", but as "an integrative field of investigation dealing with complex phenomena", IB/M has a great deal to offer and a rich research agenda.

Last but not least, we invited Jonathan $P$. Doh, who has prominently contributed to calls for reform in IB/M to offer a concluding commentary on our volume's contributions. His reflections in Chapter 12 on the previous chapters, which all offer different ways of "thinking outside the box", provide an illustration of how the disciplinary conversation can be taken forward.

\section{Notes}

1. In putting together this volume we debated at length which abbreviation would be the appropriate one to use for International Business and Management, as our contributors as well as the wide range of literature we read in relation to the state of the "field" opted for different wording. In the end we decided, in line with the title of the volume, itself the outcome of an initial negotiation with our publishers, to use $\mathrm{IB} / \mathrm{M}$. All variations referring to the discipline throughout the book have been replaced by this abbreviation.

2. There have been a number of mainstream IB/M scholars who have become actively involved in the exploration of critical IB/M themes in their research in recent years and they offer important examplars. However, the impact of this kind of publication has to date remained rather limited in the core of the field.

3. Theoretical disputes between mainstream and critical scholars may therefore be not so much purely theoretically driven as fundamentally about different political understandings, triggered by a deeper discord between the two IB/M camps about whether "global capitalism" as we know it can be reformed at all or requires a radical or even revolutionary overhaul.

\section{References}

Adler, P.S., Forbes, L.C. and Willmott, H. (2007). Critical management studies. Academy of Management Annals, 1(1): 119-179. 
Aharoni, Y. and Brock, D. (2010). International business research: Looking back and looking forward. Journal of International Management, 16(1): 5-15.

Alvesson, M., Bridgman, T. and Willmott, H. (Eds) (2009). The Oxford Handbook of Critical Management Studies. Oxford: Oxford University Press.

Buckley, P. (1996). The role of management in international business theory: A meta-analysis and integration of the literature on international business and international management. Management International Review, 36: 7-54.

Buckley, P. (2002). Is the international business research agenda running out of steam? Journal of International Business Studies, 33: 365-373.

Buckley, P., Doh, J. and Benischke, M. (2017). Towards a renaissance in international business research? Big questions, grand challenges, and the future of IB scholarship. Journal of International Business Studies, 48(9): 1045-1064.

Cairns, G.M. (2019). Critical engagement in international business: Creating meaning for a broad constituency. critical perspectives on international business, 15(2/3): 262-272.

Cairns, G. and Roberts, J. (2011). Reflections on seven years of critical perspectives on international business. critical perspectives on international business, 7(4): 289-296.

Cheng, J.L.C., Henisz, W.J., Roth, K. and Swaminathan, A. (2009). Advancing interdisciplinary research in the field of international business: Prospects, issues and challenges. Journal of International Business Studies, 40(707): 1070-1074.

Delios, A. (2017). The death and rebirth (?) of international business research. Journal of Management Studies, 54(3): 391-397.

Dörrenbächer, C. and Gammelgaard, J. (2019). Critical and mainstream international business research. critical perspectives on international business, 15(2/3): 239-261.

Dörrenbächer, C. and Geppert, M. (2017). Multinational corporations and organization theory: An introduction to post-millennium perspectives. In C. Dörrenbächer and M. Geppert (Eds), Multinational Corporations and Organization Theory: Post Millennium Perspectives (Vol. 49). Bingley: Emerald Publishing, 3-42.

Enderwick, P. (2019). Understanding cross-border crime: The value of international business research. critical perspectives on international business, 15(2/3): 119-138.

Engwall, L., Pahlberg, C. and Persson, O. (2018). The development of IB as a scientific field. International Business Review, 27(5): 1080-1088.

Ghoshal, S. and Westney, D.E. (1993). Organization Theory and the Multinational. New York: St. Martin's Press.

Griffith, D., Tamer Cavusgil, S. and Xu, S. (2008). Emerging themes in international business research. Journal of International Business Studies, 39(7): 1220-1235.

Henisz, W., Mansfield, E. and Von Glinow, M. (2010). Conflict, security, and political risk: International business in challenging times. Journal of International Business Studies, 41(5): 759-764.

Hymer, S.H. (1979). The Multinational Enterprise: A Radical Approach. Cambridge: Cambridge University Press.

Meyer, K. and Peng, M. (2016). Theoretical foundations of emerging economy business research. Journal of International Business Studies, 47(1): 3-22.

Michailova, S. and Tienari, J. (2014). What's happening to international business? University structural changes and identification with a discipline. critical perspectives on international business, 10(1/2): 51-64.

Peng, M.W. (2004). Identifying the big question in international business research. Journal of International Business Studies, 35(2): 99-108.

Roberts, J. and Dörrenbächer, C. (2012). The futures of critical perspectives on international business. critical perspectives on international business, 8(1): 4-13. 
Roberts, J. and Dörrenbächer, C. (2014). Challenging the orthodox: A decade of critical perspectives on international business. critical perspectives on international business, 10(1/2): 2-20.

Roberts, J. and Dörrenbächer, C. (2016). Renewing the call for critical perspectives on international business: Towards a second decade of challenging the orthodox. critical perspectives on international business, 12(1): 2-21.

Seno-Alday, S. (2010). International business thought: A 50-year footprint. Journal of International Management, 16(1): 16-31.

Shenkar, O. (2004). One more time: International business in a global economy. Journal of International Business Studies, 35(2): 161-171.

Witt, M.A. (2019). De-globalization: Theories, predictions, and opportunities for international business research. Journal of International Business Studies, 60: 1053-1077. 